\title{
A note from the new Editor-in-Chief
}

\section{Masakazu Haneda ${ }^{1}$}

Received: 6 April 2018 / Published online: 24 April 2018

(c) The Japan Diabetes Society 2018

It is an honor and a privilege for me to assume the role of Editor-in-Chief of Diabetology International through the decision of the Board of Directors of the Japan Diabetes Society (JDS). I follow in the large footsteps of Professor Masato Kasuga, the first Editor-in-Chief of Diabetology International.

Diabetology International was launched in November 2010 as an official peer-reviewed English journal of the JDS. The journal has been successful in providing an opportunity to present and discuss the latest information and data on diabetes not only with Japanese members of the JDS but also with the global scientific and medical community. However, the environmental situation has changed dramatically due to the worldwide burden of diabetes. According to the International Diabetes Federation (IDF) Diabetes Atlas, approximately 425 million adults in the world were living with diabetes in 2017, with 159 million in the Western Pacific region, and the number of children living with type 1 diabetes is also increasing.
As promised by Prof. Kasuga and Prof. Takashi Kadowaki, Chair of the Board of Directors, in the editorial of the first issue, Diabetology International has accepted a wide range of papers including original research and clinical articles, reviews, commentaries, and case reports, as well as editorials and reports of expert committees. This policy of the journal will continue and will expand further to cover the current status of diabetes. We welcome the submission of papers to Diabetology International from scientists, clinicians, and health professionals who are interested in research, treatment, and care of patients with diabetes around the world.

Finally, I am excited to work with the talented associate editors and editorial board to make Diabetology International an excellent journal in the field of diabetes. I am also looking forward to working together with the members of the JDS office and Springer.
Masakazu Haneda

haneda@asahikawa-med.ac.jp

1 Asahikawa Medical University, Hokkaido, Japan 